\title{
JOGOS DO PODER: RELAÇÕES SOCIOPOLÍTICAS NOS GOVERNOS DE SEPTÍMIO SEVERO E CARACALA
}

\author{
Ana Teresa Marques Gonçalves*
}

\begin{abstract}
Resumo
O objetivo deste artigo é analisar as relaçōes sociopolíticas descritas por Herodiano em sua obra, ocorridas durante os governos dos imperadores romanos Septímio Severo e Caracala. sociopolíticas

Palavras-chave: Septímio Severo; Caracala; Império Romano; Poder; relações

Na obra História do Império Romano após Marco Aurélio, de Herodiano, os senadores são mostrados como a maior força política abaixo do imperador. Mesmo quando não têm a possibilidade de escolherem o imperador, este só se legitima pela ratificação que lhe é dada pelo Senado, quando este lhe atribui o título de Augusto.

A stasis que se abre é violenta. Pescênio Nigro, governador da Síria, recebe inicialmente o apoio de boa parte dos senadores (Herod. II,7,5). Dídio Juliano compra o direito a sucessão e conta também com o apoio de parte dos senadores, pois como Herodiano afirma, ele reuniu dinheiro de amigos ${ }^{1}$ para pagar soldados para defendê-lo de Septímio Severo (Herod. II,11,7). Já Septímio Severo começou primeiro se preocupando em conquistar um forte e imbatível apoio militar, tanto que
\end{abstract}

* Professora de História Antiga e Medieval da UFG; Mestre em História Social pela USP e Doutoranda em História Econômica pela USP. 
convocou para junto de si comandantes das legiões, tribunos e a elite dos acampamentos (Herod. II,9,7), e entrou em Roma com os seus exércitos (Herod. II,13,5). Outrossim, para justificar seus atos e conseguir uma certa simpatia junto aos senadores, ele se intitula vingador de Pertinax e age contra os pretorianos assim que entra na cidade (Herod. II,9,9 e II, 13,2-3).

Ao vencer Nigro, Severo castiga os partidários deste (Herod. III,4,7-9), porém anistia os soldados, para que eles na fuga não ensinem técnicas de combate romanas aos bárbaros das fronteiras (Herod. III,4,9), mandando matar apenas os generais amigos de Nigro e seus filhos para que não pudessem vingá-los (Herod. III,5,6). Se ele anistia os legionários, em sua maioria, e refaz a Guarda Pretoriana, então os partidários perseguidos são os senadores.

No seu embate com Albino, tem mais uma vez que enfrentar uma oposição senatorial. Segundo Herodiano, os senadores apoiaram Clódio Albino contra Severo (Herod. II,5,2). No discurso proferido por Severo para as suas tropas, Herodiano diferencia a luta travada com Nigro da luta desenvolvida contra Albino:

Combatemos Nigro mais por uma inimizade necessária que por uma causa razoável, pois ele era nosso inimigo não porque tentava apoderar-se de um poder que fora nosso previamente, mas sim ao estar o Império abandonado e em litígio, cada um de nós apontou o mesmo objetivo e teve a mesma ambição. Mas Albino, ignorando pactos e juramentos, depois de obter de mim o que só se entrega a um filho, preferiu ser inimigo a amigo, rival a colega (Herod. III,6,4-5).

Severo, quando Albino se subleva, já havia sido reconhecido pelo Senado (Herod. II,9,12) e tinha inclusive forçado-o a dar o título de César a Albino. Para Herodiano, a luta que se trava antes do reconhecimento pelo Senado tem um valor moral e político e a que se trava depois tem outro, o que fundamenta ainda mais a nossa hipótese de que a fonte de poderes imperiais ainda é o Senado.

Septímio Severo dirigiu sua força contra os amigos de Albino em Roma, executando-os e confiscando as suas propriedades. Amigos estes que haviam, voluntariamente ou forçados pela necessidade, apoiado a causa de Albino (Herod. III,82-3). Ele envia diversas cartas ao Senado 
acusando homens de serem amigos de Albino e se aproveita da situação de instabilidade para eliminar todos os que se destacavam no Senado e que se sobressaíam nas províncias pela riqueza ou pela linhagem, aniquilando-os sem piedade (Herod. III,8,6-7). Prefere, segundo Herodiano, o medo dos súditos ao seu afeto (Herod. III,8,7-10). Estes súditos são certamente os senadores, pois os soldados e a plebe eram agraciados com espetáculos e distribuições de dinheiro e de alimentos (Herod. III,8,5).

Único imperador desta dinastia a morrer de doença, é sucedido pelos filhos, os quais já havia associado ao Império com o beneplácito silencioso do Senado (Herod. III,9,1) ${ }^{2}$. Caracala tentou inicialmente afastar Geta do poder, mas ao encontrar uma total oposição ao seu propósito, mais por necessidade que por convencimento aceitou a concórdia (Herod. III, 15,7).

Geta e Caracala se viram obrigados a dividir o poder, o que, de acordo com Herodiano, acabou por dividir as opiniões de todos os cidadãos que tinham uma certa posição e dignidade dentro da sociedade romana. Os dois imperadores escreviam cartas privadas para os senadores, prometendo benesses para conseguirem seu apoio. A maioria acabou por apoiar Geta, pois Caracala, como o pai, preferia a amizade baseada no medo àquela baseada no afeto (Herod. IV,3,1-4). Assim, Caracala acabou por se aproximar do exército, pois sempre que deviam efetuar nomeações para cargos militares ou civis, cada um queria promover seus próprios amigos (Herod. IV,4,1).

A situação obviamente tornou-se insustentável, já que o próprio Senado encontrava-se cindido. Como a única maneira de afastar um concorrente era a eliminação capital, Caracala manda matar Geta, alegando que este estava encabeçando uma conspiração contra ele (Herod. IV,4,4-7). Interessante notar esta alegação de Caracala. As conspirações palacianas ou conjuras cortesãs eram as principais armas usadas pelos senadores para eliminar um imperador que não the agradava. Ao denunciar esta possível conspiração, Caracala filia os senadores ao lado de Geta e tem um bom motivo para se contrapor a eles e buscar apoio entre os legionários e os pretorianos. Tanto que ele comparece ao Senado após o assassinato do irmão cercado por elementos da Guarda Pretoriana (Herod. IV,5,2) e em seu discurso afirma que: "Defender-se 
dos conspiradores não só é uma ação justa, como conta com o respaldo do costume" (Herod. IV,5,5).

Ao falar em costumes e ao tentar legitimar o seu ato mediante argumentos baseados na tradição, ele provoca uma maior confusão num Senado já bastante dividido e as opiniões se tornam controversas (Herod. IV,5,7). Para evitar a formação de uma força social de oposição, Caracala manda matar os membros da corte e os amigos de Geta, senadores de alta linhagem e fortuna, governadores e procuradores provinciais (Herod. IV,6,1-5). Não nos parece que estas eliminações tenham sido motivadas apenas visando ao confisco dos bens dos aristocratas, para que o Tesouro Público pudesse arcar com as despesas advindas do aumento de $50 \%$ promovido por Caracala no soldo dos soldados (Herod. IV,4,7), pois o próprio Herodiano afirma que este aumento foi pago imediatamente com o dinheiro acumulado nos templos e no próprio Tesouro por Septímio Severo durante o seu governo.

Os soldados estavam satisfeitos com seu governo por causa dos donativos e dos exemplos que dava, apresentando grande força física e inúmeras virtudes militares (Herod. IV,7,5-7). Para os senadores, os amigos de Caracala eram os soldados; por isso viam sua amicitia como falsa e baseada na adulação e não no respeito.

Os elementos eqüestres, por sua vez, aparecem tão mesclados aos senadores na obra de Herodiano que quase não são citados como um grupo social distinto daqueles. São vistos como um reservatório de futuros senadores. Eles só são citados como um grupo em momentos festivos.

Sua existência é percebida, por exemplo, durante o ritual de apoteose de Septímio Severo, quando:

Os membros mais nobres da ordem eqüestre e os jovens escolhidos da ordem senatorial levantam o leito, levam-no pela Via Sacra e o expõem no fórum antigo [...] (Herod. IV,2,4).

Quando se terminou de empilhar os produtos aromáticos e todo o lugar se encheu de perfume, tem lugar uma cavalgada em volta da pira, e toda a ordem equiestre cavalga em círculo [...] (Herod. IV,2,9). 
São rituais festivos, mas também políticos. Com a execução da apoteose, Caracala e Geta se tornam filhos de um divus, o que legitima ainda mais o seu poder.

Alguns autores, como o clássico C.W. Keyes, defendem que no II e III séculos há uma transferência de poderes da ordem senatorial para a ordem eqüestre, principalmente no que se refere aos governos das províncias e aos comandos legionários (Keyes, 1915, p. 1), baseandose na leitura das epígrafes e não em fontes textuais. Para ele, Septímio Severo teria iniciado este processo, intencionando enfraquecer o Senado pela ascensão dos eqüestres (Keyes, 1915, p. 32).

Contudo a partir da própria releitura de Herodiano, a nossa opinião vai mais de encontro com aquela defendida por P.A. Brunt, que coloca que: em primeiro lugar, os eqüestres estavam empregados em postos civis e militares desde Augusto (De Martino, 1974:533); em segundo lugar, o fato de que no III século os eqüestres suplantaram os senadores nos cargos de alta responsabilidade é quase ignorado pelos autores antigos, como se isto fosse um desenvolvimento natural das duas carreiras; e em terceiro lugar, é difícil separar os eqüestres dos senadores, já que eles estão num verdadeiro processo de fusão, sendo também difícil identificar uma rivalidade intrínseca existente entre as ordens (Brunt, 1983, p. 1 e 65), já que o final hierárquico de uma é o início da outra. ${ }^{3}$

Quando falamos do exército romano, temos que fazer uma espécie de abstração epistemológica, pois os líderes deste exército pertencem aos grupos anteriormente citados, ou seja, aos senadores $\mathrm{e}$ aos elementos eqüestres. Só que ao ocuparem cargos militares, estes homens passam a fazer parte de uma corporação que gera uma certa identidade em seus componentes. Como coloca Paul Petit (Petit, 1974, p. 60), o exército acaba por possuir um "espírito de corpo". Eles são os homens em armas, que têm por função básica defender os limites do Império ${ }^{4}$. Enquanto os senadores almejam um "imperador-amigo", o exército, que também apresenta uma grande diferenciação nos seus membros e um certo ideário ético comum, compartilhando valores como a coragem, a obediência, a ousadia, a lógica estratégica, entre outros, deseja o governo de um "líder provedor".

O exército nada mais é do que um grupo de legiões, estacionadas em vários cantos do Império Romano e que nem sempre agem de forma conjunta. Ao falar que o exército apoiou um imperador ou se opôs a ele, 
temos que relativizar esta informação para partes do exército, e quando possível, para legiões específicas.

A Guarda Pretoriana, mais do que uma mera parte do exército, constitui-se desde o início numa tropa de elite que se distinguia das outras cohortes por meio das relações específicas que mantinha com o imperador e dos privilégios que detinha. ${ }^{5}$ Até o governo de Septímio Severo, ela era formada apenas por cidadãos romanos recrutados somente na Itália, que prestavam um serviço de dezesseis anos e que recebiam um soldo bastante superior ao dos legionários. O próprio Herodiano coloca que os Pretorianos eram soldados especiais, escolhidos entre todos e possuidores de uma grande corpulência (Herod. V,4,8). Deste modo, as legiões alocadas nas fronteiras formavam forças sociopolíticas que se diferenciavam em muitos aspectos da representada pela Guarda Pretoriana, inclusive em relação aos interesses que representavam na luta pelo poder, apesar de, como dissemos anteriormente, ambas serem formadas por homens em armas.

A dicotomia legiões alocadas nas fronteiras/Guarda Pretoriana pode ser constatada em várias passagens das obras em questão. A busca de um patrono, como bem enfatizam Terry Johnson e Christopher Dandecker (1990, p. 228), traz também a competição e não apenas a integração e o controle social (Wallace-Hadrill, 1990, p. 85), a coesão social e a reciprocidade (Saller, 1982, p. 69). O imperador ou o candidato ao cargo imperial torna-se um patrono esperando conseguir este controle e esta coesão social (Garnsey; Saller, 1987, p. 149-150), mas cada grupo tem o interesse de colocar o seu patrono no poder para adquirir um maior número de benesses. Como afirma Fergus Millar (1992, p. 275), ${ }^{6}$ o exercício da patronagem foi desde o início um elemento essencial dentre as funções do imperador. Os soldados se opunham a todos os imperadores que, por motivos vários, fugiam aos seus deveres de patrono. ${ }^{7}$

Esta competição para alçar ao poder o seu patrono ${ }^{8}$, colocava freqüentemente as legiões umas contra as outras e a Guarda Pretoriana contra as legiões. Septímio Severo ao se dizer vingador de Pertinax, não pode refazer os laços de patronagem/clientela com o grupo que matou aquele que ele diz representar. Então, ele se vê obrigado a reformar esta Guarda, buscando trazer novos clientes para si. Antes de entrar em Roma chega mesmo a fazer um discurso destinado a inflamar os ânimos de suas legiões contra as coortes pretorianas (Herod. II,10,2-6). 
Passerini comenta que Severo decidiu que a Guarda Pretoriana seria formada por legionários vindos de todo o Império, sendo convocados pelo próprio imperador, que substituía, assim, o sistema dos engajamentos voluntários. Ele pretendia, por intermédio deste expediente, substituir os italianos e alguns poucos provinciais mais romanizados por soldados devotados a sua pessoa, oferecendo-lhes como recompensa por esta lealdade a entrada nas fileiras pretorianas, mais bem pagas do que as outras tropas. Além disso, criou o imposto da annona militaris, para pagar estas inovações (Devreker, 1971:358). Buscou, desta forma, aumentar a sua clientela, e com isso a sua segurança pessoal, vinculando a força política da Guarda Pretoriana à sua própria força política.

Caracala organizou uma guarda pessoal formada por germanos (Herod. IV $, 13,6)^{9}$, pois confiava mais neles que na guarda montada por seu pai, mesmo herdando as relações de patronagem e tendo ela the demonstrado ser fiel no caso de Plauciano (Herod. II,12,9-11).

Nenhum imperador desde Augusto deixou de procurar obter o apoio das legiões. Como ironizam Le Gall e Le Glay $\left(1989\right.$, p. 556) ${ }^{10}$, Septímio Severo devia seu trono ao exército, mas ele não era o primeiro! O famoso processo de militarização do Império não pode ser visto apenas como o uso da patronagem militar para ascender e permanecer no poder. Ele é mais profundo e demonstra por que a oposição senatorial é cada vez mais reacionária, ou seja, cada vez mais ela se baseia na defesa dos valores do passado para criticar os príncipes vigentes, que preferem o apoio militar ao seu. Como coloca Le Roux, o apoio do Senado tornou-se complementar àquele dado pelas tropas, enquanto no passado era o contrário $^{11}$. Sabendo que tem ao seu lado um grupo armado que sempre pode optar por um novo patrono, o príncipe acabava procurando garantir pelo menos a simpatia do Senado e do povo romano (Le Roux, 1987, p. $45)$.

Já a Plebe Urbana de Roma é um grupo extremamente heterogêneo, como demonstram Zvi Yavetz (1984), em sua obra La Plèbe et le Prince, e P.A. Brunt (1981, p. 87-117), em seu texto La Plebe Romana. E as nossas fontes literárias tratam pouco deste sujeito. Quando ele aparece citado, normalmente é apresentado como insolente, inconstante, entre outros adjetivos desabonadores, como podemos perceber nestas passagens: 
Todas as massas são certamente propensas à mudança, mas o povo romano, formado por uma grande multidão composta por homens de diversas procedências, pode mudar de opinião ainda com mais extraordinária facilidade (Herod. VII,7,1).

As desgraças de quem em aparência é afortunado e rico não somente não preocupam o povo, como este em certas ocasiões se alegra [...] porque sente inveja ante o poder e a sorte (Herod. VII,3,5).

Yavetz (1986, p. 143) comenta que estas posições são típicos clichês do ideário senatorial. Por ser vista como invejosa, propensa à mudança, inconstante e facilmente persuadida, a plebe não precisava ser estimulada à ação mediante longos discursos, como os que eram feitos para os soldados e os senadores. Uma leitura superficial dos autores antigos pode levar a pensar que, no Império Romano, a plebe deixou de ser um ator político (Yavetz, 1984:28).

No entanto, pela própria releitura atenta da obra em questão, vemos que ela reagia às ações imperiais, apoiando os imperadores ou se opondo a eles, que buscavam conquistá-la através da distribuição de bens e de dinheiro e do oferecimento de jogos. Assim, o imperador assumia a função de patrono, trocando benesses econômicas por apoio político. No período severiano, a plebe nunca chegou a agir para derrubar um imperador, mas a preocupação que todos os imperadores deste período tiveram em deixá-la satisfeita indica que ela ainda tinha algum poder político.

Septímio Severo distribui dinheiro e promove espetáculos para a plebe assim que chega a Roma (Herod. II,14,5-6). Na crise com Albino, mais uma vez reparte dinheiro para a plebe (Herod. II,8,5 e III,8,7) e oferece espetáculos, os chamados Jogos Triunfais (Herod. II,8,7-10). O próprio Herodiano ressalta que estas atitudes visavam a ganhar o apoio do povo para o seu governo (Herod. III,8,10). Repete estes expedientes ainda uma vez mais ao finalizar a campanha do Oriente, após ser recebido em triunfo (Herod. III,10,2). Caracala, entretanto, só se preocupou em agradar o exército e acabou sofrendo a oposição da plebe (Herod. IV,6,5).

Deste modo, acreditamos que a plebe urbana de Roma já era um ator político no período severiano, e que, apesar de não interferirem diretamente na escolha e na deposição dos imperadores, seus componentes também participavam das forças de oposição aos gover- 
nantes que não eram bons patronos, ou seja, que não exerciam bem a sua Liberalitas, a sua generosidade ${ }^{12}$. Para a plebe o bom imperador, isto é, aquele ao qual ela não se oporia, deveria ser um grande distribuidor de benesses com equidade. Ela se opõe e demonstra o seu descontentamento através de tumultos, como os feitos no circo.

Esta plebe urbana só se reúne quando seus interesses mais prementes estão comprometidos: a sua sobrevivência, que era facilitada pelas distribuições imperiais e pela manutenção do abastecimento, principalmente de trigo. Porém é importante ressaltar que ela tem o poder de se mobilizar e de se unir quando os seus interesses estão sendo prejudicados de alguma forma. Como coloca Yavetz (1984, p. 187), o soberano devia satisfazer as necessidades fundamentais do povo, para responder à imagem que esta plebe fazia do soberano ideal.

Em vários momentos da narrativa analisada, encontramos também referências a grupos provinciais que se movimentaram para apoiar candidatos a imperador ou governantes já aclamados ou se opor a eles. Desde Cômodo já vemos a presença de provinciais na Corte, no Senado ou atuando politicamente a partir de suas próprias províncias ${ }^{13}$. Nesta parte do trabalho, entretanto, nos limitaremos à participação sociopolítica dos grupos que ainda permanecem nas províncias, e de lá demonstram as suas convicções políticas.

Como afirma Mason Hammond (1956, p. 126), muitos imperadores buscaram o apoio das províncias para ascenderem ao poder supremo, tornando-se em alguns casos a voz destas províncias. Elas já haviam sofrido até o período severiano um profundo e marcante processo de romanização ${ }^{14}$, como bem destacam Sandra Gozzoli (1987, p. 81108) e Fergus Millar (1983, p. 76-96). Este último enfatiza a relação de patronagem que sempre marcou a relação de alguns imperadores com algumas cidades provinciais, na qual benesses econômicas deveriam ser retribuídas na forma de um devotamento político e militar. Lembremonos também de que a Liberalitas imperial poderia ser dirigida a particulares ou a comunidades (Manning, 1985, p. 78), de acordo com as necessidades vigentes.

Para Millar (1983, p. 77), três fatores marcaram a relação de Roma com as cidades provinciais: o exército, já que muitos legionários eram de origem provincial; a patronagem, que vinculava as cidades ao imperador; e as leis romanas, que integravam as cidades sob uma mesma 
tutela de caráter jurídico. Sandra Gozzoli, por sua vez, acrescenta elementos a esta análise. Para esta autora, não se pode esquecer o apoio que Roma, desde o período republicano, dava às aristocracias provinciais, esperando delas fidelidade (Gozzoli, 1987, p. 82). Além disso, a própria presença de legiões nestas províncias poderia servir para a manutenção da estabilidade social e da ordem romana em seu interior (Gozzoli, 1987, p. 91).

De acordo com G.W. Bowersock, a principal forma de oposição assumida pelas províncias no Principado foram as sedições locais, ou seja, tumultos promovidos por algumas cidades provinciais como forma de protesto por medidas econômicas, políticas ou sociais tomadas pelos imperadores. Portanto, as cidades provinciais se manifestariam através de movimentos de subversão da ordem constituída pelos romanos (Bowersock, 1987, p. 291-293). Ao relermos criticamente a obra de Herodiano, encontramos outras formas de estas cidades provinciais se inserirem no cenário político imperial, principalmente nos momentos de sucessão de governantes.

Os grupos provinciais aproveitavam a disputa pelo poder, como a ocorrida no início do período severiano, para escolher um dos contendores, e desta forma garantirem a concessão de benefícios por parte daqueles que foram apoiados por eles. É sem dúvida uma espécie de patronagem, pois trocas são feitas entre membros de esferas desiguais.

Não obstante, estes grupos provinciais nem sempre lucravam com estas escaramuças entre os pretendentes ao poder supremo. Sabemos que várias cidades optavam por um lado e se opunham ao outro devido a inimizades antigas que contrapunham cidades de uma mesma região, principalmente no que concerne à parte oriental do Império. Se uma cidade se colocasse a favor de um candidato, a sua cidade inimiga se colocava imediatamente contra ele e apoiava o outro pretendente. Este é o caso por exemplo das cidades de Nicomédia e Niceia na Bitínia (Herod. III, 2,7-10); de Laodicéia e Antioquia na Síria (Herod. III,3,3); e de Tiro e Berito na Fenícia (Herod. III,3,5). Estas apoiavam os seus escolhidos com o fornecimento de víveres, dinheiro e de homens para integrarem as legiões competidoras (Herod. III,2,10).

O problema para estas cidades se dava quando os seus candidatos eram derrotados no conflito armado. Nigro, por exemplo, quando começa a perder para Severo, manda lanceiros mauritanos ${ }^{15}$ e arqueiros para 
matarem a população e incendiar e pilhar as cidades que começaram a mudar de lado no meio da batalha, ou seja, que o atraiçoaram, ou ainda que haviam feito uma insolente rebelião (Herod. III,3,3-5). Ao vencer, Septímio manda destruir Bizâncio e Antioquia, cidades provinciais cujos grupos sociais the haviam feito oposição. Suas populações são submetidas a cidades aliadas. Contudo, Septímio, ao mesmo tempo em que as destrói, manda reconstruir as cidades que haviam sido destruídas por Nigro (Herod. III,6,9).

Entretanto, uma das passagens mais interessantes da obra de Herodiano sobre o relacionamento mantido entre os imperadores e os grupos provinciais, que misturava respeito, ódio e subversão, é a transcrição da visita de Caracala a Alexandria. Ele é recebido pela população com uma chuva de flores e tochas de fogo para alumiarem o seu caminho (Herod. IV,8,7-8). Todavia, apesar de toda esta recepção, o objetivo de Caracala era acabar com os alexandrinos.

Segundo Herodiano, este ódio de Caracala pelos alexandrinos se devia ao fato de estes fazerem piadas, colocando em evidência os erros do imperador (Herod. IV,9,4). Acreditamos que este ódio seja mais profundo e se relacione com o fato de os alexandrinos num passado não muito distante terem feito oposição a Caracala. Lembremo-nos de que, de acordo com o próprio relato de Herodiano, quando Geta ainda vivia, os dois irmãos pensaram em dividir o Império entre si. Caracala ficaria com a Europa e Geta com a Ásia. A capital da parte imperial de Caracala seria Roma, onde ficariam para auxiliá-lo os senadores europeus, e ele teria direito também de organizar um acampamento de legiões fiéis a si em Bizâncio. Geta, por sua vez, montaria um acampamento militar para suas tropas na Calcedônia da Bitínia, seria auxiliado pelos senadores originários da Ásia, e firmaria a capital da sua parte imperial na cidade da Antioquia ou, exatamente e não por acaso, em Alexandria (Herod. IV,3,5-9). ${ }^{16}$

Portanto, Caracala deveria enfrentar uma oposição fomentada por grupos alexandrinos, que outrora foram favoráveis a seu irmão. Ao atacar a cidade de Alexandria, ele teria procurado eliminar parte da oposição que se organizava contra ele. Ele ordenou que os jovens da cidade se apresentassem para formarem uma falange. Quando estes se reuniram na praça principal da cidade, ele se retirou com sua guarda pessoal e mandou que algumas legiões que o acompanhavam atacassem 
os jovens. De acordo com Herodiano, o rio Nilo ficou vermelho de sangue com o massacre (Herod. IV,9,4-8).

O poder político e a legitimidade de um governo não se apóiam somente em impostos e no exército, mas também nas concepções e nas crenças humanas. A população imperial não adere necessariamente a um soberano em particular, mas a um soberano idealizado, que simboliza a ordem imutável do mundo (Hopkins, 1978, p. 232). Por isso, Septímio Severo e Caracala buscaram desenvolver no jogo do poder representações e práticas que fortalecessem e definissem seus laços com os grupos sociais que os cercavam. Além da prática de distribuição de benesses, estes imperadores também se preocuparam em fortalecer e enfatizar suas representações como bons amigos, patronos e líderes provedores de seus súditos.

\footnotetext{
Abstract

The objective of this article is to analyse the social-politic relationship rapported by Herodian's work, in the Septimus Severus and Caracalla's Imperial Roman Governments.

Key words: 1. Septimus Severus; 2. Caracalla; 3. Roman Empire; 4. power; 5. social-political relations.

\section{Notas}

1. De amigos e não de clientes. Isto fica bem claro na narrativa de Herodiano. E amigo de senador tinha que ser um homem do mesmo nível social que ele.

2. Durante a campanha da Bretanha, Septímio Severo deixa Geta cuidando da justiça e da administração civil do Império, ajudado por conselheiros, isto é, os amigos mais velhos de Severo (Herod. III,14,9). Assim, vemos a presença de elementos senatoriais próximos de Geta, antes mesmo da morte do pai.

3. Não nos esqueçamos de que vários Prefeitos do Pretório foram contemplados com a concessão dos ornamenta pretoria ou consularia, com as adlectiones inter consulares ou pretores, ou com a Dignitas Senatoria, passando mesmo em alguns casos a usar o título de uir clarissimus (Durry,1938:176).
} 
4. Le Roux defende que o exército, na ausência de centros especializados de formação, era uma "escola" administrativa, um lugar de trocas e de discussões políticas, uma sociedade onde se forjava uma cultura (Le Roux, 1987, p. 48).

5. Para P. Le Roux, baseando-se na obra de J.B. Campbell: The Emperor and the Roman Army, a Guarda Pretoriana não era um corpo de elite no sentido militar do termo e sua influência política não era superior àquela das legiões (Le Roux,1987, p. 43).

6. Millar vê inclusive a ascensão de homens aos cargos civis e militares, mediante a recomendação imperial, e a passagem de eqüestres para a ordem senatorial como atribuições da patronagem do imperador (Millar, 1992, p. 284 e 291).

7. Sobre o fenômeno sociológico das clientelas coletivas dos Príncipes, vide: Gagé,1964, p. 71-81. Neste capítulo, o autor analisa como a patronagem se constitui numa das bases essenciais do Principado.

8. Herodiano comenta que as legiões que apoiavam Nigro, ao perderem a batalha da baía de Isso, perderam também a oportunidade de eleger um imperador (Herod. III,4,5).

9. Homens selecionados por sua força e aparência (Herod. IV,7,3).

10. Sobre a importância do elemento militar desde o início do Principado, vide Gagé,1964, p. 250 e Gara,1986, p. 349-350. Esta última autora argumenta que não foi a importância do elemento militar que se modificou no III século, mas o modo como o exército passou a lidar com os imperadores.

11. Na ideologia senatorial, de um lado deveria estar o imperador e os senadores, detentores da cultura e do poder, e do outro os soldados, vistos como pobres e pouco cultivados, incapazes de se revoltarem sem a ajuda de seus superiores (Le Roux, 1987, p. 47).

12. Sobre a virtude da Liberalitas, sua reabilitação no período imperial e sua conotação francamente política, vide: Manning, 1985, p. 73-83.

13. Sábios vêm das províncias para educar Cômodo (Herod. I, 2,1).

14. Segundo Sandra Gozzoli, é exatamente na passagem do II para o III século que se opera a completa romanização das províncias (Gozzoli, 1987, p. 108). Opinião esta compartilhada por Sherwin-White, que acrescenta que é no período dos Severos que se realiza a fusão e a equalização entre o leste e o oeste imperiais, incrementadas pelas várias adlectiones de orientais promovidas por estes governantes 
(Sherwin-White, 1939, p. 216). Acreditamos que um sintoma deste processo seja exatamente a promulgação do Edito de Caracala em 212 , mesmo que este autor defenda que os motivos de Caracala para levar adiante este Edito tenham sido inteiramente fiscais (SherwinWhite, 1939, p. 277).

15. Sobre a relação desenvolvida entre a Mauritânia e seus famosos lanceiros e arqueiros com os imperadores severianos, vide: Speidel, 1972, p. 850-860; Arnheim, 1972, p. 33. Mauritânia era uma província governada por membros da ordem eqüestre escolhidos pelos imperadores.

16.Segundo Herodiano este projeto de divisão do Império foi rechaçado por Júlia Domna (Herod. IV,3,9).

\section{Fontes}

ERODIANO.Storia dell'Impero Romano dopo Marco Aurelio. Testo e versione di Filippo Cassola. Firenze: Sansoni,1967.

HERODIANO. Historia del Imperio Romano después de Marco Aurélio. Traducción y notas por Juan J. Torres Esbarranch. Madrid: Gredos,1985.

HÉRODIEN. Histoire de l'Empire Romain après Marc-Aurèle. Traduit et commenté par Denis Roques. Paris:Les Belles Lettres,1990.

\section{Referências Bibliográficas}

ALFOLDY, G. A História Social de Roma. Lisboa: Presença, 1989.

ALSTON, R. Roman Military Pay from Caesar to Diocletian. JRS. London, 84: 113-123, 1994.

ARNHEIM, M.T.W. The Senatorial Aristocracy in the Later Roman Empire. Oxford: at University, 1972.

BALANDIER, G. Antropologia Política. São Paulo: Difel, 1969. . O Poder em Cena. Brasília: Edunb, 1980. As Dinâmicas Sociais: Sentido e Poder. São Paulo: Difel, 1982.

L'Anthropologie Sociale et Politique et les Sciences de l'Antiquité. $B A G B$. Paris, 2: 213-220,1975.

. et al. Civilizações: Entrevistas do Le Monde. São Paulo: Ática, 1989. p. 147-153. 
BAYET, J. La Religion Romana. Madrid: Cristiandad, s.d.

BOBBIO, N. (org.). Dicionário de Política. Brasília: Edunb,1986.

BOURDIEU, P. O Poder Simbólico. Rio de Janeiro: Bertrand, 1989.

BOWERSOCK, G.W. Greek Intellectuals and the Imperial Cult in the

Second Century A.D. In: Le Culte des Souverains dans l'Empire

Romain. Genève: Fondation Hardt, 1973. t.19, p.179-207.

The Mechanics of Subversion in the Roman Provinces. In:

Opposition et Résistances à l'Empire d'Auguste à Trajan. Genève:

Fondation Hardt, 1987. t.33, p.291-317.

BRUNT, P.A. Princeps and Equites. JRS. London, 73: 42-75, 1983.

La Plebe Romana. In: FINLEY, M.I. (ed.). Estudios sobre Historia Antigua Madrid: Akal, 1981. p.87-118.

CAMPBELL, B. The Marriage of Soldiers under the Empire. JRS. London, 68: 153-166, 1978.

DE MARTINO, F. Storia della Costituzione Romana. Napoli: Dott. Eugenio Jovene, 1974. v.4, parte 1.

. Storia della Costituzione Romana. Napoli: Dott. Eugenio Jovene, 1975. v.4, parte 2.

DEVELIN, R. The Army Pay Rises under Severus and Caracalla, and the Question of Annona Militaris. Latomus. Bruxelles, t.30, n.3: 687$695,1971$.

DEVREKER, J. Une Inscription Inédite de Caracalla à Pessinonte. Latomus. Bruxelles, t.30, n.2:352-362, 1971.

DURRY, M. Les Cohortes Prétoriennes. Paris: E. de Boccard, 1938. Les Empereurs comme Historiens d'Auguste à Hadrien. In: Pour l'Étude de l'Antiquité Classique. Genève: Fondation Hardt, 1956. t.4, p.215-235.

FINLEY, M.I. Historia Antigua: Problemas Metodológicos. Barcelona: Crítica, 1986.

A Política no Mundo Antigo. Rio de Janeiro: Zahar, 1985.

La Censure dans l'Antiquité. RH. Paris, 533: 3-20, 1980.

FISHWICK, D. The Development of Provincial Ruler Worship in the Western Roman Empire. ANRW. Berlin, v.2,n.16,parte 2: 1242-1253, 1981.

GAGÉ, J. Les Classes Sociales dans l'Empire Romain. Paris: Payot, 1964. 
GARA, A. La Mobilità Sociale nell'Impero. Athenaeum. Pavia, 2: 335358, 1991.

GARNSEY, P., SALLER, R. The Roman Empire. London: Duckworth, 1987.

GOZZOLI, S. Fondamenti Ideali e Pratica Politica del Processo di Romanizzazione nelle Province. Athenaeum. Pavia, 2: 81-108, 1987.

GRIMAL, P. Les Erreurs de la Liberté. Paris: Les Belles Lettres, 1989.

HAMMOND, M. Composition of the Senate A.D. 68-235. JRS. London, 47:74-81, 1957.

. The Transmission of the Powers of the Roman Emperor from the Death of Nero in A.D. 68 to that of Alexander Severus in A.D. 235. MAAR. Rome, 24: 118-128,1956.

HOPKINS, K. Conquistadores y Esclavos. Barcelona: Península, 1978. Movilidad de la Élite en el Imperio Romano. In: FINLEY, M.I. (ed.). Estudios sobre Historia Antigua. Madrid: Akal, 1981. p.119136.

JACQUES, F., SCHEID, J. Rome et l'Intégration de l'Empire. Paris: PUF, 1990.

JOHNSON, T., DANDEKER, Ch. Patronage: Relation and System. In: WALLACE-HADRILL, A. (ed.). Patronage in Ancient Society. London: Routledge, 1990. p.219-238.

KÁDÁR, Z. Julia Domna comme Assyrié Kythereia et Seléné. ACD. Debrecen, 2: 101-108,1966.

KAPLAN, A., LASSWELL, H. Poder e Sociedade. Brasília: Edunb, 1979.

KEYES, C.W. The Rise of the Equites. Princeton: University Press, 1915.

LE GALL, J. Rome. Ville de Fainéants? REL. Paris, 49: 266-277, 1972. ; LE GLAY, M. L'Empire Romain. Paris: PUF, 1989.

LE GLAY, M., VOISIN, J.-L., LE BOHEC, Y. Histoire Romaine. Paris: PUF, 1991.

LE ROUX, P. L'Empereur et 1'Armée Romaine. REL. Paris, 63: 42-49, 1987.

MACMULLEN, R. Enemies of the Roman Order. London: Routledge, 1992.

. Roman Government's Response to Crisis. New Haven: Yale University Press, 1976. 
. Soldier and Civilian in the Later Roman Empire. Cambridge: Harvard University Press, 1963.

. Christianizing the Roman Empire. New Haven: Yale University Press, 1984.

- Les Rapports entre les Classes Sociales dans l'Empire Romain. Paris: Seuil,1974.

MANNING, C.E. Liberalitas - The Decline and Rehabilitation of a Virtue. $G \& R$. Oxford, v.32, n.1:73-83, 1985.

MAZZARINO, S. Il Pensiero Storico Classico. Roma: Laterza, 1974. v.2, n.2.

MILLAR, F. The Emperor in the Roman World. London: Duckworth, 1992.

Empire and City, Augustus to Julian: Obligations, Excuses and Status. JRS. London, 73: 76-96, 1983.

A New Approach to the Roman Jurists. JRS. London, 76: 272280,1986.

PASSERINI, A. Le Coorti Pretorie. Roma: Angelo Signorelli, 1939.

PETIT, P. A Paz Romana. São Paulo: Edusp, Pioneira, 1989.

Histoire Générale de l'Empire Romain. Paris: Seuil, 1974. v. 1,2 e 3.

SALLER, R.P. Personal Patronage under the Early Empire. Cambridge: University Press, 1982.

Patronage and Friendship in Early Imperial Rome: Drawing the Distinction. In: WALLACE-HADRILL, A. (ed.). Patronage in Ancient Society. London: Routledge, 1990. p. 49-62.

SHAW, B.D. Tombstones and Roman Family Relations in the Principate: Civilians, Soldiers and Slaves. JRS. London, 74: 124-146, 1984.

Patronage and Friendship in Early Imperial Rome: Drawing the Distinction. WALLACE-HADRILL, A. (ed.). Patronage in Ancient Society. London: Routledge, 1990. p. 49-62.

, SHAW, B.D. Tombstones and Roman Family Relations in the Principate: Civilians, Soldiers and Slaves. JRS. London, 74: 124-146, 1984.

SHERWIN-WHITE, A.N. The Roman Citizenship. Oxford: at the Clarendon Press, 1939. 
SPEIDEL, M.A. Roman Army Pay Scales. JRS. London, 82: 87-106, 1992.

SPEIDEL, M.P. Legionary Cohorts in Mauretania. The Role of Legionary Cohorts in the Structure of Expeditionary Armies. ANRW. Berlin, v.2, n. 10, parte 2: $850-862,1972$.

SYME, R. Roman Papers. Oxford: Clarendon Press, 1991. t.6.

THE CAMBRIDGE Ancient History. The Imperial Crisis and Recovery. Cambridge: University Press, 1939. v.12.

TURCAN, R. Vivre à la Cour des Césars. Paris: Les Belles Lettres, 1987

. Le Culte Impérial au III ${ }^{\circ}$ Siècle. ANRW. Berlin, v.2, n.16, parte 2: 997-1083, 1980.

WALLACE-HADRILL, A. Civilis Princeps: Between Citizen and King. JRS. London, 72: 32- 48, 1982.

. Patronage in Roman Society: from Republic to Empire. In: Patronage in Ancient Society. London: Routledge, 1990. p.63-88.

YAVETZ, Z. La Plèbe et le Prince. Paris: Découverte, 1984.

. The Urban Plebs in the Days of the Flavians, Nerva and Trajan. In: Opposition et Résistances à l'Empire d'Auguste à Trajan. Genève: Fondation Hardt, 1987. t.33, p.135-181.

ZEHNACKER, H. Tensions et Contradictions dans l'Empire ao I $^{\circ}$ Siècle: Les Témoignages Numismatiques. In: Opposition et Résistances à l'Empire d'Auguste à Trajan. Genève: Fondation Hardt, 1987. t.33, p. 321-357. 